\title{
Identificação de áreas temáticas para subsidiar pesquisa sobre sustentabilidade em indústrias
}

\author{
Identification of thematic areas in order to support research about sustainability in \\ industries
}

\author{
Camila Kahlau ${ }^{15}$ \\ Ana Carolina Greef ${ }^{16}$ \\ Sidarta Ruthes de Lima ${ }^{17}$ \\ Rafael Henrique Holzbach ${ }^{18}$ \\ Marilia de Souza ${ }^{19}$
}

Artigo recebido para publicação em Out./2013 e aceito para publicação em Ago./2014.

\section{RESUMO}

Identificou-se a necessidade de traduzir a sustentabilidade em aspectos passíveis de aplicação pela indústria e de avaliação nesta. O objetivo deste estudo é identificar áreas temáticas que subsidiem o desenvolvimento de instrumento de pesquisa sobre ações de sustentabilidade nas indústrias do Paraná. Como fontes para pesquisa exploratória, utilizaram-se documentos referenciais e sobre indicadores de sustentabilidade. Como procedimentos metodológicos, destacam-se as análises categorial e temática. Para tanto, aplicaram-se as etapas de pesquisa e análise de fontes de informação; definição de categorias de análise e suporte tecnológico; categorização do conteúdo e identificação de temas; elaboração de áreas temáticas. A pesquisa resultou em temas representativos da sustentabilidade, tratados quanto à nomenclatura, sobreposições e pertinência à indústria. Chegou-se a uma proposta de quinze áreas temáticas de sustentabilidade, a serem aplicadas em investigação junto a indústrias no Paraná.

Palavras-chave: Sustentabilidade. Desenvolvimento sustentável. Indústria. Análise de conteúdo. Indicadores de sustentabilidade.

\section{ABSTRACT}

The need of translating sustainability into aspects that can be applied by industry and evaluated in it was identified. The goal of this research is to identify thematic areas that support the development of a research instrument focused on sustainability activities applied by Parana's industries. Reference

15 Graduada em Planejamento Turístico pelo Instituto Federal de Educação, Ciência e Tecnologia de Goiás (2011). Mestranda em Tecnologia pela Universidade Tecnológica Federal do Paraná - UTFPR. Pesquisadora dos Observatórios SESI SENAI IEL do Sistema FIEP, no Programa Bússola da Sustentabilidade. E-mail: camila.kahlau@sesipr.org.br.

16 Graduada em Gestão da Informação (2010) e Mestre em Ciência, Gestão e Tecnologia da Informação (2013) pela Universidade Federal do Paraná - UFPR. Professora efetiva na Escola Técnica da Universidade Positivo (UP) e Pesquisadora dos Observatórios SESI SENAI IEL do Sistema FIEP, no Programa Bússola da Sustentabilidade.E-mail: ac.greef@gmail.com.

17 Graduada em Administração pela Universidade Federal de Santa Maria - UFSM (2005) e Mestre (2007) e Doutorando em Tecnologia pela Universidade Tecnológica Federal do Paraná - UTFPR. Atualmente é coordenador e pesquisador dos Observatórios SESI SENAI IEL do Sistema FIEP. E-mail: sidarta.lima@sesipr.org.br.

18 Mestre em Tecnologia pela Universidade Tecnológica Federal do Paraná - UTFPR (2012), possui graduação em Gestão da Informação pela Universidade Federal do Paraná - UFPR (2002) e especialização em Gestão Empresarial pela Universidade Estadual do Oeste do Paraná - UNIOESTE (2005). E-mail: rafaelholzbach@gmail.com.

19 Possui graduação em Desenho Industrial (1993) pela Fundação Mineira de Arte Aleijadinho, mestrado em Sciences de IHomme et Technologie (1997) pela Universtité de Technologie de Compiègne e doutorado em Sciences Mécaniques pour IIngénieur (2001) pela Université de Technologie de Compiègne. Gerente dos Observatórios de Prospecção e Difusão de Tecnologias (SENAI-PR), de Prospecção e Difusão de Iniciativas Sociais (SESI-PR) e de Desenvolvimento Industrial (IEL-PR). Atua no Grupo de Pesquisa Prospecção de Tecnologia e Desenvolvimento Tecnológico Regional. E-mail: marilia.souza@fiepr.org.br. 
documents and contents about sustainability indicators were used as sources for the exploratory research. Categorical and thematic analysis are highlighted as methodological procedures. Stages related to research and analysis of information sources; definition categories of analysis and technological support; categorization of the content and theme identification; and proposal of thematic areas were applied. The study has delivered a set of representative subjects of sustainability, treated concerning about denomination, overlapping and relevance to the industry. A proposal of fifteen thematic areas of sustainability was reached, to be used in research with industries in Parana.

Keywords: Sustainability. Sustainable development. Industries. Content analysis. Sustainability indicators.

\section{INTRODUÇÃO}

A sustentabilidade e os modelos de desenvolvimento orientados a esta, têm sido objeto de reflexões, discussões e esforços por diferentes atores, desde indivíduos a nações. Ainda assim, os desafios são complexos quanto à harmonização entre os interesses dos sistemas sociais com a conservação dos sistemas ambientais.

Inicialmente o termo sustentabilidade apareceu vinculado aos sistemas ambientais e ao entendimento das condições de conservação destes, evidenciados em publicações da International Union for Conservation of Nature (IUCN) ou de autores no espaço acadêmico. Porém, a contínua soma de novos atores ao desafio de amadurecer indicadores para o desenvolvimento de territórios, fez com que a sustentabilidade refletisse também questões pertinentes aos sistemas humanos.

Dessa forma, aspectos de sustentabilidade chegaram também ao cenário industrial, propondo, basicamente, o fornecimento de produtos e serviços voltados a maximizar contribuições ao desenvolvimento econômico e bem-estar humano, bem como minimizar impactos negativos sobre os mesmos fatores (UNITED NATIONS INDUSTRIAL DEVELOPMENT ORGANIZATION, 2002).

O setor empresarial é percebido como incentivador e um dos pilares para o alcance do desenvolvimento sustentável, devido às suas potenciais contribuições na formulação de políticas públicas e de metas (BARATA, 2007). Neste sentido, o Sistema Federação das Indústrias do Estado do Paraná (Sistema FIEP) integra estes esforços e busca o protagonismo na construção do desenvolvimento sustentável, mobilizando empresas e propondo ferramentas que as apoiem nesse tema. Assim, estimula a criação de ambientes propícios à concepção de uma nova indústria, que avança alinhada com a sustentabilidade no presente e com foco nas gerações futuras (FEDERAÇÃO DAS INDÚSTRIAS DO ESTADO DO PARANÁ, 2013). 
Entre outras iniciativas alinhadas à temática, o Sistema FIEP concebeu em 2011 o Programa Bússola da Sustentabilidade, que tem por objetivo promover o alinhamento entre as estratégias de negócios e as atividades das indústrias no Paraná a aspectos sociais, ambientais, econômicos, culturais e espaciais de sustentabilidade. Organizado em projetos complementares e contando com o suporte de tecnologias de informação e comunicação, o Programa idealiza a realização de uma pesquisa para coleta de dados das indústrias do Paraná, bem como a sensibilização e orientação dos empresários e executivos sobre o tema.

Este artigo trata, especificamente, do projeto voltado à identificação de áreas temáticas comumente relacionadas à sustentabilidade, com potencial para investigação junto a indústrias instaladas no Paraná. Dentre os procedimentos metodológicos utilizados, destaca-se o uso da análise categorial e temática, baseada no método de análise de conteúdo.

\section{REFERENCIAL TEÓRICO}

Preocupações sobre desigualdades sociais, ameaças e desastres ambientais, em grande parte, decorrentes do modelo de desenvolvimento vigente na maioria dos países a partir da revolução industrial, afloraram nas décadas de 1960 e 1970 questionamentos e reflexões sobre rumos e consequências do crescimento estritamente econômico (BAZZO, LINSINGEN, TEIXEIRA, 2003; CUTCLIFFE, 2003). Desde então, governos, empresas, organizações não governamentais, institutos de pesquisa e outros, têm se engajado na busca por modelos de desenvolvimento equilibrados, que garantam as condições básicas de funcionamento dos sistemas humanos e ambientais para as gerações atuais e futuras.

Em meio a estes esforços e de acordo com a literatura pesquisada, surgem na década de 1980 o termo "sustentável" e correlações, como "sustentabilidade" e "desenvolvimento sustentável". Cunhado inicialmente pela International Union for Conservation of Nature (IUCN) em 1980, o entendimento desses termos foi ampliado e popularizado no documento chamado "Nosso Futuro Comum", conhecido como Relatório de Brundtland, publicado em 1987 pela Comissão Mundial sobre Meio Ambiente e Desenvolvimento (BARONI, 1992).

Dessa forma, o termo "desenvolvimento sustentável" complementa suas bases de fundamentação no referido relatório, por meio dos seguintes objetivos- 
chave: crescimento renovável; mudança de qualidade do crescimento; satisfação das necessidades essenciais por emprego, alimento, energia, água e saneamento básico; garantia de um nível sustentável de população; conservação e proteção da base de recursos; reorientação da tecnologia e gestão do risco, e reorientação das relações econômicas internacionais (COMISSÃO MUNDIAL SOBRE MEIO AMBIENTE E DESENVOLVIMENTO, 1988). Essa formulação, aliada ao documento conhecido como Agenda 21, figura entre as definições de "desenvolvimento sustentável” mais citadas e aceitas (BARONI, 1992; VAN BELLEN, 2002).

Apesar da trajetória desde a primeira definição de "desenvolvimento sustentável", ainda não se obteve consenso a respeito de sua abordagem, já que a diversidade de atores e interesses envolvidos nesta temática atribui abrangência tal à mesma, que dificulta sua operacionalização. Neste sentido, autores (SILVA, 2005; VAN BELLEN, 2002) têm sugerido desdobrar o desenvolvimento sustentável em dimensões para facilitar a construção de soluções e instrumentos de avaliação, sem perder a essência relacional destas.

Dentre as propostas para representar o desenvolvimento sustentável, em geral, são destacadas as dimensões ambiental, econômica e social. Demais sugestões consideram também as dimensões material, ecológica, legal, cultural, política, psicológica (BOSSEL, 1999) e institucional (UNITED NATIONS, 2007). Já segundo Sachs (1993), a sustentabilidade tem como estrutura cinco dimensões: social, econômica, ecológica, geográfica, e cultural, sinteticamente apresentadas no Quadro 1. 
Quadro 1 - Dimensões da sustentabilidade propostas por Sachs

\begin{tabular}{|c|c|}
\hline DIMENSÄO & CRITÉRIOS \\
\hline Social & $\begin{array}{l}\text { - Alcance de um patamar razoável de homogeneidade social; } \\
\text { - Distribuição de renda justa; } \\
\text { - Emprego pleno e/ou autônomo com qualidade de vida decente: } \\
\text { - Igualdade no acesso aos recursos e serviços sociais. }\end{array}$ \\
\hline Econômica & $\begin{array}{l}\text { - Desenvolvimento econômico intersetorial equilibrado; } \\
\text { - Segurança alimentar; } \\
\text { - Capacidade de modernização continua dos instrumentos de produção; } \\
\text { - Razoável nivel de autonomia na pesquisa cientifica e tecnológica; } \\
\text { - Inserção soberana na economia internacional. }\end{array}$ \\
\hline Ecológica & $\begin{array}{l}\text { - Preservação do potencial do capital natureza na sua produção de recursos } \\
\text { renováveis; } \\
\text { - Limitar o uso dos recursos não-renováveis. }\end{array}$ \\
\hline Espacial & - Melhor distribuição territorial de assentamentos humanos e atividades econômicas. \\
\hline Cultural & $\begin{array}{l}\text { - Mudanças no interior da continuidade (equilibrio entre respeito à tradição e } \\
\text { inovação); } \\
\text { - Capacidade de autonomia para elaboração de um projeto nacional integrado e } \\
\text { endógeno; } \\
\text { - Autoconfiança combinada com abertura para o mundo. }\end{array}$ \\
\hline
\end{tabular}

Fonte: adaptado de Sachs (1993).

A proposta de Sachs (1993) foi selecionada para orientar o estudo, considerados os argumentos: amplitude da proposta em relação às três perspectivas de sustentabilidade (ambiental, social e econômica) comumente utilizadas na área; alinhamento das perspectivas apresentadas com o escopo do Programa de pesquisa em questão, contemplando reflexões sobre cultura e espaço geográfico no contexto industrial a ser investigado; e alinhamento institucional entre a proposta e expectativas quanto à pesquisa.

\section{AVALIAÇÃO DE ASPECTOS DE SUSTENTABILIDADE}

Além da citada dificuldade consensual de abordagem, outro desafio pertinente ao desenvolvimento sustentável perpassa a criação de métodos e ferramentas para avaliar seu progresso em diferentes dimensões, além de prover informações relevantes à tomada de decisão nas organizações (HARDI; ZDAN, 1997). O Instituto Brasileiro de Geografia e Estatística (IBGE) aponta que os indicadores de desenvolvimento sustentável são tidos como essenciais para guiar a ação e subsidiar o acompanhamento e a avaliação do progresso alcançado no tema. Ressalta-se que tais ferramentas e indicadores servem como um meio para alcançar a sustentabilidade e não como fins em si mesmos - acrescentam mais pelo que apontam do que por seu valor absoluto e são mais úteis quando analisados em 
conjunto do que individualmente (INSTITUTO BRASILEIRO DE GEOGRAFIA E ESTATÍSTICA, 2010).

No contexto mundial, a avaliação do desenvolvimento sustentável conta com direcionamentos já consolidados no documento intitulado Indicators of sustainable development: framework and methodologies, publicado pela Comission on Sustainable Development (CSD) da Organização das Nações Unidas (ONU). Em sua terceira edição, o documento também conhecido como Livro Azul, propõe 50 indicadores essenciais, 46 indicadores complementares e recomendações metodológicas para avaliação do desenvolvimento sustentável (UNITED NATIONS, 2007). Um dos benefícios decorrentes da referida publicação é a disponibilização de informações consolidadas, unificadas e que permitem comparações entre países. No Brasil em particular, a principal pesquisa na área que se utiliza da referência da ONU, é conduzida pelo IBGE (INSTITUTO BRASILEIRO DE GEOGRAFIA E ESTATÍSTICA, 2010).

Por fim, os indicadores devem simplificar as informações sobre fenômenos complexos, aprimorando o entendimento e a comunicação sobre estes. Podem ser quantitativos ou qualitativos, sendo que eventualmente 0 uso de indicadores qualitativos é apontado como mais adequado por autores para avaliar experiências referentes à sustentabilidade (VAN BELLEN, 2002). Ainda segundo o autor, poucos são os sistemas de indicadores que abordam especificamente o tema, sendo estes em sua maioria de caráter experimental, visto que problemas complexos pertinentes ao desenvolvimento sustentável exigem ferramentas com dimensões interligadas, bem como indicadores inter-relacionados.

Documentos de referência sobre o tema, contendo princípios e critérios de sustentabilidade em geral, são difundidos nas comunidades científica e técnica para amenizar a lacuna citada por Van Bellen (2002). Embora existam documentos de mensuração de aspectos sustentabilidade nas organizações, como iniciativas do Instituto Ethos (2007) e do GRI, documentos sobre princípios e critérios de sustentabilidade específicos às organizações ainda necessitam ser consolidados.

\section{DESENVOLVIMENTO SUSTENTÁVEL NA INDÚSTRIA}

Entre os atores engajados no desafio de promover o desenvolvimento sustentável, destacam-se empresas e indústrias, apontadas como fundamentais à definição de metas inseridas nesse conceito de desenvolvimento, devido à força 
exercida sobre os formuladores de políticas públicas (BARATA, 2007). Outros autores afirmam que o desenvolvimento sustentável chega às organizações privadas por meio da exigência dos órgãos públicos e dos clientes que demandam uma posição responsável quanto às suas ações, a fim de minimizar impactos ambientais, promover programas sociais e viabilizar a manutenção econômica (ARAÚJO et al., 2006).

A UNIDO compartilha a responsabilidade para promoção e aceleração do desenvolvimento industrial sustentável nos países em desenvolvimento e economias em transição. Conforme a agência, é possível formular uma definição básica aceita por todos os atores, governo, sociedade, empresa, entre outros que refletem os princípios da ecoeficiência ${ }^{20}$ social com equidade. Logo, o desenvolvimento sustentável na indústria é o fornecimento de bens e serviços visando maximizar contribuições ao desenvolvimento econômico e bem-estar humano, minimizando os impactos negativos sobre o meio-ambiente, a força de trabalho e a sociedade (UNITED NATIONS INDUSTRIAL DEVELOPMENT ORGANIZATION, 2002).

Esse conceito de desenvolvimento é fortalecido no âmbito empresarial a partir da criação do Conselho Empresarial Brasileiro para o Desenvolvimento Sustentável, responsável pelo primeiro relatório de sustentabilidade do Brasil (MEZOMO et al., 2010). No relatório, o progresso do desenvolvimento sustentável é considerado positivo, devido à criação de vantagens competitivas e oportunidades. Em contrapartida, é ressaltada a necessidade da criação de uma nova ética na forma de fazer negócios.

Quanto ao setor industrial, a Confederação Nacional das Indústrias aborda o desenvolvimento sustentável contemplando a eficiência produtiva no uso dos recursos, que promove o equilíbrio das três dimensões clássicas - o crescimento econômico, a erradicação da pobreza e conservação do meio ambiente -, com abrangência da dimensão cultural (CONFEDERAÇÃO NACIONAL DA INDÚSTRIA, 2012).

20 Para a UNIDO, os princípios da ecoeficiência privilegiam processos de ciclos de produção fechados, que evitam o desperdício e possuem rastreabilidade dos produtos do início ao fim, por meio do desenvolvimento e difusão de tecnologias fidedignas ao propósito de reduzir impactos ao meio ambiente, como técnicas de inovação socioambiental. 


\section{PROCEDIMENTOS METODOLÓGICOS}

Conforme critérios para classificação de estudos propostos por Gil (2010), esta pesquisa se enquadra quanto à sua finalidade, como aplicada. Quanto ao objetivo, a investigação é exploratória, e quanto ao método empregado, é classificada como bibliográfica para coleta de dados secundários (GIL, 2010).

Para a operacionalização desta pesquisa, aplicaram-se as análises categorial e temática, oriundas do método de análise de conteúdo. Bardin (2011, p. 31) define tal método como um "conjunto de técnicas de análise das comunicações" que se utiliza de procedimentos sistemáticos e objetivos para descrever o conteúdo de mensagens. Segundo a autora, a análise de conteúdo objetiva a inferência de informações relacionadas ao contexto e às condições de produção de um tema, utilizando para tanto indicadores quantitativos e qualitativos deste.

No método supracitado, a técnica de análise categorial é a mais antiga, frequentemente utilizada e operacionalizada por meio do desmembramento de um texto íntegro em categorias agrupadas de forma analógica (BARDIN, 2011). A autora afirma que entre as possibilidades de categorização, a análise temática é eficaz visto que identifica núcleos de significado componentes da comunicação, cuja existência e ocorrência têm também significado para o estudo em questão (BARDIN, 2011).

Observando essas orientações metodológicas e zelando pela organização da pesquisa, esta foi segmentada em etapas, ilustradas na Figura 1, desenvolvida segundo orientações de Gil (2010) sobre a organização de procedimentos de um estudo. Tanto essas etapas quanto o projeto em específico, fazem parte de um contexto mais amplo, conformado por outros projetos do Programa Bússola da Sustentabilidade. 
Figura 1 - Diagrama das etapas de pesquisa

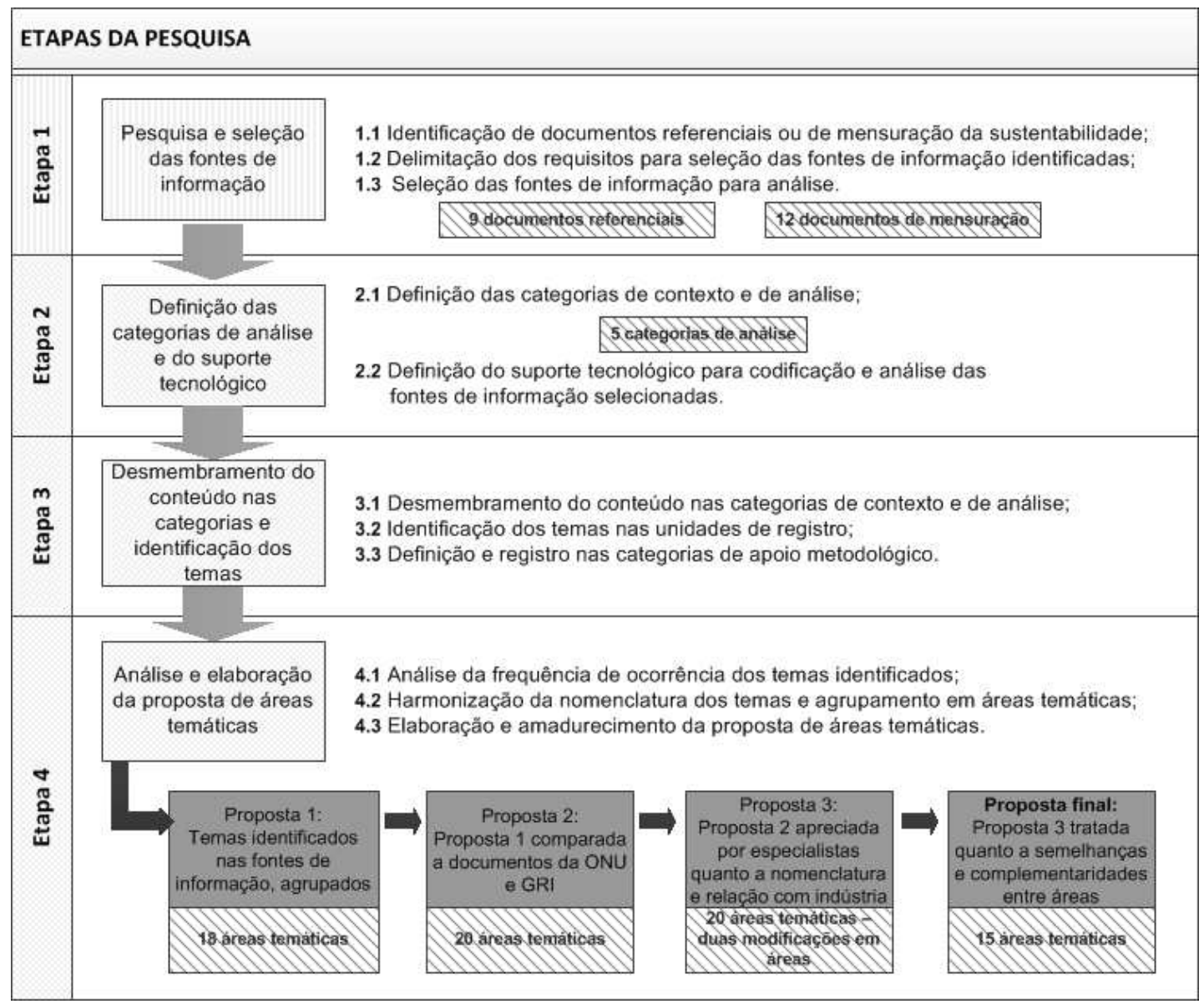

Fonte: Sistema FIEP - Observatórios SESI SENAI IEL (2012).

$\mathrm{Na}$ etapa inicial, foram identificados por meio de pesquisa exploratória documentos tidos como referenciais no tema sustentabilidade e também documentos orientados à mensuração do tema. Para a seleção destes documentos foram observados os requisitos contidos no Quadro 2.

Quadro 2 - Requisitos para seleção das fontes de informação
\begin{tabular}{|l|l|c|}
\hline REQUISITO & DESCRIÇĂo \\
\hline Requisito 1 & O documento deve resultar do debate e da busca de consenso entre diferentes atores da sociedade \\
\hline Requisito 2 & O documento deve conter de maneira explicita, principios, critérios ou indicadores relacionados à sustentabilidade \\
\hline Requisito 3 & O documento deve ser utilizado por diferentes instituições em âmbito nacional ou internacional \\
\hline Requisito 4 & O documento deve, preferencialmente, ser orientado à indústrias ou à empresas \\
\hline Requisito 5 & O documento, em conjunto com os demais, deve considerar uma ampla variedade de temas relativos à sustentabilidade \\
\hline Requisito 6 & O documento deve considerar dimensões alinhadas às contempladas e delimitadas para a pesquisa \\
\hline
\end{tabular}

Fonte: Sistema FIEP - Observatórios SESI SENAI IEL (2012).

A delimitação dos requisitos para seleção das fontes de informação a serem analisadas, ocorreu de maneira direcionada por 3 fatores, a saber: aprendizado 
resultante de iniciativas similares, como a do Instituto ETHOS (2007); valorização de documentos que resultassem de debate e da busca de consenso entre diferentes atores da sociedade, conforme contribuições de Hardi e Zdan (1997); e alinhamento com o escopo e com as delimitações do Programa Bússola da Sustentabilidade.

Sem a pretensão de ser uma análise exaustiva sobre fontes de informação relacionadas ao tema, os esforços desta primeira etapa metodológica, resultaram na identificação de 29 possíveis fontes e na seleção de 21 destas, conforme apresentado na próxima seção.

$\mathrm{Na}$ segunda etapa da pesquisa definiram-se as categorias para a análise e também o suporte tecnológico. Quanto às categorias, Bardin (2011) sugere a utilização de categorias de contexto e de análise. Segundo a autora, as categorias de contexto auxiliam na compreensão e significação dos dados de maneira objetiva e possibilitando a reposição destes em seus contextos (BARDIN, 2011). Estas categorias não são consideradas na análise temática. Por sua vez, as categorias de análise, como o nome sugere, são aquelas utilizadas para a análise temática (BARDIN, 2011).

As referidas categorias de análise foram definidas com base na proposta de perspectivas principais da sustentabilidade de Sachs (1993) e delimitações do Programa Bússola da Sustentabilidade. Já as categorias de contexto foram definidas com base em estudos similares, como o de Louette (2008) e Farfus et al. (2010), e também de maneira proposital, em função das necessidades visualizadas pela equipe de pesquisadores do Programa. Tanto as categorias de contexto como as definidas para a análise são apresentadas na seção posterior, sobre os resultados.

Ainda nesta etapa, foi definido o suporte tecnológico a ser utilizado para codificação e análise dos resultados. Pesquisa sobre soluções disponíveis nesta direção levou a optar pelo software de análise qualitativa de dados Atlas.ti. $O$ software suporta diversos formatos de arquivos e dispõe de ferramentas para codificação, categorização e análise de dados, recursos que contribuíram para a seleção do software, além do suporte de informações disponível para sua utilização.

Após estas ações, foi possível iniciar a terceira etapa da pesquisa - o desmembramento do conteúdo e identificação temática. Para a organização do conteúdo das fontes de informação selecionadas nas categorias de contexto e de análise definidas, foram observadas as regras sugeridas por Bardin (2011), a saber: homogeneidade - as categorias devem conter elementos de conteúdos similares; exaustividade - contemplar e esgotar a totalidade da fonte; exclusividade - os 
elementos similares não devem figurar categorias distintas; e adequação e pertinência - os elementos devem ser adaptados ao conteúdo e ao objetivo das categorias.

Mesmo observando as regras sugeridas pela autora para desmembramento do conteúdo nas categorias definidas, cabe resaltar que em alguns casos, os elementos de conteúdo foram adequados às categorias mais próximas aos seus significados, ou propositalmente atribuídos a uma categoria em particular. Em outros casos, o conteúdo foi distribuído em mais de uma categoria ou delimitado em função do foco da pesquisa. Segundo Bardin (2011), mesmo que as regras auxiliem na fragmentação objetiva e sistemática do conteúdo, raramente estas são integralmente aplicáveis.

Para registrar as escolhas e delimitações realizadas durante a análise do conteúdo das fontes de informação selecionadas, foram desenvolvidas categorias específicas, chamadas categorias de apoio metodológico.

Já para o desmembramento do conteúdo nas categorias de análise, Bardin (2011) sugere o uso das unidades de registro e de contexto. A primeira representa uma "unidade de significação codificada e corresponde ao segmento de conteúdo considerado unidade de base, visando à categorização e a contagem frequencial" (BARDIN, 2011, p. 104). Nesta pesquisa, a unidade de registro adotada foi o tema, descrito como a "unidade de significação que se liberta naturalmente de um texto analisado segundo certos critérios relativos à teoria que serve de guia à leitura" (BARDIN, 2011, p. 105).

Por sua vez, a unidade de contexto "serve de unidade de compreensão para codificar a unidade de registro", com tamanho suficiente para subsidiar o entendimento do significado da unidade de registro (BARDIN, 2011, p. 107). Nesta pesquisa, a unidade de contexto foi formada pelos enunciados dos princípios, critérios e indicadores, que basearam a análise temática e os resultados desta.

Na quarta e última etapa, realizaram-se a análise e a elaboração da proposta de áreas temáticas para o Programa Bússola da Sustentabilidade. Os temas identificados e codificados foram armazenados em unidades de registro e alocados nas categorias definidas para análise, permitindo identificar a frequência de ocorrência dos temas por categoria e ordená-los de acordo com este dado.

A partir dessa ordenação, foram necessários esforços de tratamento, harmonização dos temas e elaboração da proposta de áreas temáticas. Inicialmente, com base no tesauro da UNESCO, foi tratada e padronizada a nomenclatura 
utilizada nos códigos para os temas identificados. Na sequencia, estes temas foram agrupados de acordo com sua similaridade e abrangência, gerando a primeira proposta de áreas temáticas a serem investigados pelo Programa Bússola da Sustentabilidade.

Esta primeira proposta foi analisada e comparada com temas trabalhados por outras iniciativas de sustentabilidade, a saber: Conferência da ONU sobre Meio Ambiente e Desenvolvimento e Global Reporting Iniciative (GRI). Para análise dos temas trabalhados pela ONU, foi selecionado o documento The future we want, resultante de conferência sobre meio ambiente e desenvolvimento realizada no Brasil (UNITED NATIONS, 2012). Este foi selecionado devido à sua atualidade, método de elaboração, organização em temas e relevância internacional. Para análise dos temas abordados pelo GRI, foi selecionado o documento Sustainability Reporting Guidelines, orientação internacional para elaboração de relatórios de sustentabilidade (GLOBAL REPORTING INITIATIVE, 2012).

Esses esforços deram origem à segunda proposta de temas a serem investigados, que foi apreciada por especialistas alocados em outros programas de pesquisa, na instituição executora deste estudo. Os especialistas foram selecionados a partir de critérios como experiência na indústria e em pesquisa. As contribuições fornecidas por cada um deles foram guiadas por reflexões acerca da nomenclatura das áreas temáticas, seus impactos e relação com a indústria. Após adequação, portanto, ao público alvo e às demais delimitações, foi gerada uma terceira proposta de áreas temáticas.

Observada essa proposta, percebeu-se proximidade entre certas áreas, devido a semelhanças ou complementaridades entre dados de sua contextualização e conceitos relacionados. Analisando-se o contexto industrial, foco de aplicação das áreas definidas, observou-se que não necessariamente estas deveriam ser tratadas com o detalhamento obtido em sua terceira versão, já que a complementaridade entre temas como "Água" e "Mares e Oceanos", levaria à sobreposição de conceitos idênticos e aplicados de forma idêntica na indústria. Essa reflexão resultou na proposta definitiva de áreas temáticas de sustentabilidade a serem investigadas em indústrias no Paraná. 


\section{APRESENTAÇÃO E DISCUSSÃO DOS RESULTADOS}

A primeira etapa dos procedimentos metodológicos tratou da seleção das fontes de informação para a análise de seu conteúdo. Para tanto, foram identificados documentos contendo princípios, critérios (referenciais) e indicadores (de mensuração) de sustentabilidade.

O Quadro 3 contém os documentos identificados e tomados como referenciais para a análise de conteúdo, sua respectiva autoria e orientação a princípios ou critérios de sustentabilidade.

\begin{tabular}{|c|c|c|}
\hline DOCUMENTOS REFERENCIAIS & AUTORIA & ORIENTAÇĀO \\
\hline Diretrizes da OCDE para as empresas multinacionais & OCDE & Principios \\
\hline Declaração de principios sobre as empresas multinacionais e a política social & OIT & Principios \\
\hline Global Compact & ONU & Principios \\
\hline Objetivos de desenvolvimento do milênio & ONU & Principios \\
\hline Carta da Terra & ONU & Principios \\
\hline Agenda 21 & ONU & Principios \\
\hline Critérios essenciais de RSE & ETHOS & Critérios \\
\hline Declaraçāo do Rio sobre meio ambiente e desenvolvimento & ONU & Principios \\
\hline Conferência sobre meio ambiente humano & ONU & Principios \\
\hline
\end{tabular}

Fonte: Sistema FIEP - Observatórios SESI SENAI IEL (2012).

O Quadro 4 contém documentos identificados como orientados à mensuração de sustentabilidade para a análise de conteúdo.

Quadro 4 - Seleção de documentos de mensuração

\begin{tabular}{|c|c|c|}
\hline DOCUMENTOS DE MENSURAÇĀO & AUTORIA & ORIENTAÇĀO \\
\hline Global Reporting Initiative & GRI & \multirow{12}{*}{ Indicadores } \\
\hline CSD Indicators of Sustainable Development & ONU & \\
\hline Indicadores de Desenvolvimento Sustentável & IBGE & \\
\hline Indicadores ETHOS de Responsabilidade Social Empresarial & ETHOS & \\
\hline OECD Sustainable Manufacturing Toolkit & OCDE & \\
\hline Iniciativa Latinoamericana e Caribenha para o Desenvolvimento Sustentável & UNESCO & \\
\hline Rumo a um desenvolvimento sustentável: indicadores ambientais & OCDE & \\
\hline Environmental Sustainability and Industry & AL GROUP & \\
\hline From Transparency to Performance - Industry-based sustainability reporting & HARVARD & \\
\hline Sustainable Development in the European Union - 2011 & EUROSTAT & \\
\hline Measuring Progress Sustainable Development Indicators 2010 & DEFRA & \\
\hline Indice de Sustentabilidade Empresarial & BM\&FBOVESPA & \\
\hline
\end{tabular}

Fonte: Sistema FIEP - Observatórios SESI SENAI IEL (2012).

Selecionadas as fontes de informação às quais seria aplicada a análise de conteúdo (Quadros 3 e 4), passou-se à composição das categorias definidas para condução da mesma análise (Quadro 5). 
Quadro 5 - Categorias de análise de conteúdo

\begin{tabular}{|l|l|}
\hline \multicolumn{1}{|c|}{ CATEGORIAS DE ANÁLISE } & DESCRIÇÃO \\
\hline Aspectos ecológicos & Relacionada ao meio ambiente e às interações humanas \\
\hline Aspectos sociais & Focada no ser humano, suas interaçōes enquanto individuo e ser em sociedade \\
\hline Aspectos econômicos & Orientada a questões financeiras e econômicas \\
\hline Aspectos culturais & Observa a identidade cultural, princípios e valores que guiam indivíduos e suas sociedades \\
\hline Aspectos geográficos ou espaciais & Focada no espaço analitico e suas características geográficas \\
\hline
\end{tabular}

Fonte: Sistema FIEP - Observatórios SESI SENAI IEL (2012).

Definidas as categorias para a análise de conteúdo (Quadro 6), passou-se à codificação dos conteúdos dos documentos selecionados. Nessa codificação, trechos de princípios, critérios ou indicadores relacionados à sustentabilidade foram selecionados de cada uma das fontes de informação. Cada trecho foi composto de modo a sintetizar o significado do código criado, para a posterior utilização na pesquisa junto às indústrias no Paraná.

Os códigos foram criados de forma padronizada, visando a organização de sua compilação posterior. Como padrão, definiu-se que os códigos deveriam indicar seu documento de origem e até três palavras-chave representativas, evitando o uso de verbos ou preposições nestas.

A codificação foi iniciada por meio de leitura e estudo de cada documento selecionado como fonte, indicando seu foco em princípios, critérios ou indicadores de sustentabilidade. Após esta etapa, códigos com temas afins foram agrupados em conjuntos chamados famílias, intituladas de forma a sintetizar o conteúdo a elas pertinente. Essas, por sua vez, foram agrupadas em superfamílias conforme a perspectiva de sustentabilidade a elas relacionada, notadamente social, econômica, ecológica, cultural ou espacial.

Finalizada a codificação dos documentos selecionados, partiu-se para a construção das áreas temáticas de sustentabilidade a partir dos códigos e famílias obtidos. Para tanto, todos os 1068 códigos obtidos foram quantificados em planilha, tomando como ponto de partida a frequência de sua ocorrência. Neste momento, verificou-se novamente a aderência de cada código à sua citação, para melhor indicar a área temática de sustentabilidade à qual ambos, código e citação, se referiram. 
Tomadas estas medidas, a análise do conteúdo resgatado na forma de códigos resultou em 18 áreas temáticas, eventualmente com subáreas frequentemente observadas nos documentos referenciais e de mensuração. Esta proposta inicial de áreas temáticas é apresentada no Quadro 6.

\begin{tabular}{|c|c|}
\hline PROPOSTA 1 DE ÁREAS TEMÁTICAS & SUBTEMAS \\
\hline 1. Agua & Fornecimento; Tratamento; Consumo; Poluiçāo \\
\hline 2. Atmosfera & Qualidade e poluição do ar; Inventário de emissões \\
\hline 3. Consumo & Deveres; Padrões de consumo; Consumidor \\
\hline 4. Clima & Näo foram identificados subtemas para esta área \\
\hline 5. Demografia & Năo foram identificados subtemas para esta área \\
\hline 6. Direitos & $\begin{array}{l}\text { Saúde: Infância; Juventude; Segurança; Combate à pobreza } \\
\text { Terceira idade; Diversidade; Comunidade; Direitos humanos }\end{array}$ \\
\hline 7. Recursos naturais & Espécies ameaçadas; Conservaçăo \\
\hline 8. Educação & Formação inicial; Capacitação em serviço; Escolaridade \\
\hline 9. Efeitos atividades humanas & Não foram identificados subtemas para esta área \\
\hline 10. Governança & Governança pública e corporativa; Compromissos éticos \\
\hline 11. Inovação & Ciência e tecnologia; Divulgação; Cultura \\
\hline 12. Oceanos, mares e regiōes costeiras & Recursos halie̊uticos e marinhos \\
\hline 13. Produção & Insumos; Cadeia produtiva; Setores produtivos; Produtividade \\
\hline 14. Recursos energéticos & Consumo e fontes de energia; Eficiência energética \\
\hline 15. Residuos & Substâncias perigosas; Residuos sólidos; Lixo; Responsabilidade \\
\hline 16. Solo & Degradação; Poluiçăo; Conservação; Cultivo; Politicas \\
\hline 17. Trabalho & Relações e condições de trabalho; Emprego \\
\hline 18. Transporte & Näo foram identificados subtemas para esta área \\
\hline
\end{tabular}

Fonte: Sistema FIEP - Observatórios SESI SENAI IEL (2012).

Para cada uma das áreas listadas no Quadro 6 criou-se uma ficha descritiva dos códigos identificados, sua ocorrência, fontes de informação e percentual das citações selecionadas nessas fontes.

Assim, foi possível ratificar a composição de cada área temática com base no conteúdo selecionado. Para complementar tal ação, foram selecionados os documentos The future we want e Sustainability Reporting Guidelines, entre as fontes de informação apresentadas nos Quadros 3 e 4, como base para comparação e análise das áreas propostas. Comparação, esta, apresentada no Quadro 7. 


\begin{tabular}{|c|c|c|c|}
\hline $\begin{array}{l}\text { PROPOSTA } 1 \text { DE } \\
\text { ÁREAS TEMÁTICAS }\end{array}$ & $\begin{array}{c}\text { ONU - THE FUTURE WE WANT } \\
(2012)\end{array}$ & $\begin{array}{c}\text { GRI - SUSTAINTABILITY } \\
\text { REPORTING GUIDELINES (2011) }\end{array}$ & $\begin{array}{l}\text { PROPOSTA } 2 \text { DE } \\
\text { AREAS TEMÁTICAS }\end{array}$ \\
\hline 1. Água & Água e saneamento & Água & 1. Água \\
\hline 2. Atmosfera & & & 2. Atmosfera \\
\hline \multirow{2}{*}{ 3. Consumo } & \multirow{2}{*}{ Produção e consumo sustentável } & Segurança e saúde do consumidor & \multirow{2}{*}{ 3. Consumo } \\
\hline & & Privacidade do consumidor & \\
\hline 4. Clima & Mudanças climáticas & & 4. Clima \\
\hline \multirow[b]{2}{*}{ 5. Demografia } & Turismo sustentável & & \multirow[b]{2}{*}{ 5. Demografia } \\
\hline & $\begin{array}{l}\text { Cidades e assentamentos humanos } \\
\text { sustentáveis }\end{array}$ & & \\
\hline \multirow{8}{*}{ 6. Direitos } & \multirow{3}{*}{$\begin{array}{l}\text { Igualdade de gêneros e } \\
\text { empowerment da mulher }\end{array}$} & $\begin{array}{l}\text { Diversidade e igualdade de } \\
\text { oportunidades }\end{array}$ & \multirow{3}{*}{$\begin{array}{l}\text { 6. Diversidade e } \\
\text { Igualdade de gênero }\end{array}$} \\
\hline & & $\begin{array}{l}\text { Remuneração igual para homens e } \\
\text { mulheres }\end{array}$ & \\
\hline & & Não discriminação & \\
\hline & Erradicação da pobreza & Práticas de investimento e aquisição & \multirow{5}{*}{ 7. Direitos } \\
\hline & \multirow{4}{*}{ Saúde e população } & Direitos indigenas & \\
\hline & & Avaliação & \\
\hline & & Remediação & \\
\hline & & Comunidades locais & \\
\hline \multirow{3}{*}{ 7. Recursos naturais } & Florestas & Biodiversidade & \multirow{3}{*}{ 8. Recursos naturais } \\
\hline & \begin{tabular}{|l|} 
Biodiversidade \\
\end{tabular} & Global & \\
\hline & Montanhas & STudal & \\
\hline 8. Educação & Educação & Formação e educação & 9. Educação \\
\hline $\begin{array}{l}\text { 9. Efeitos atividades } \\
\text { humanas }\end{array}$ & Redução do risco de desastres & Compliance & $\begin{array}{l}\text { 10. Efeitos atividades } \\
\text { humanas }\end{array}$ \\
\hline \multirow{6}{*}{ 10. Governança } & $\begin{array}{l}\text { Pequenos Estados insulares em } \\
\text { desenvolvimento }\end{array}$ & Desempenho econômico & \multirow{5}{*}{ 11. Governança } \\
\hline & Países menos desenvolvidos & Presença de mercado & \\
\hline & $\begin{array}{l}\text { Países em desenvolvimento sem } \\
\text { acesso ao mar }\end{array}$ & Impactos econômicos indiretos & \\
\hline & África & Políticas públicas & \\
\hline & \multirow{2}{*}{ Esforços regionais } & Comportamento anticompetitivo & \\
\hline & & Corrupção & 12. Corrupção \\
\hline 11. Inovação & & Comunicações de marketing & 13. Inovação \\
\hline $\begin{array}{l}\text { 12. Oceanos, mares e } \\
\text { regiöes costeiras }\end{array}$ & Mares e oceanos & & $\begin{array}{l}\text { 14. Oceanos, mares e } \\
\text { regiões costeiras }\end{array}$ \\
\hline \multirow{3}{*}{ 13. Produção } & & Materiais & \multirow{3}{*}{ 15. Produção } \\
\hline & & Produtos e serviços & \\
\hline & & Rotulagem de produtos e serviços & \\
\hline $\begin{array}{l}\text { 14. Recursos } \\
\text { energéticos }\end{array}$ & Energia & Energia & $\begin{array}{l}\text { 16. Recursos } \\
\text { energéticos }\end{array}$ \\
\hline 15. Resíduos & Produtos químicos e resíduos & Emissões, efluentes e lixo & 17. Resíduos \\
\hline \multirow{3}{*}{ 16. Solo } & $\begin{array}{l}\text { Agricultura sustentável, segurança } \\
\text { alimentar e nutricional }\end{array}$ & & \multirow{3}{*}{ 18. Solo } \\
\hline & $\begin{array}{l}\text { Desertificação, degradação de solos } \\
\text { e seca }\end{array}$ & & \\
\hline & Mineração & & \\
\hline \multirow{7}{*}{ 17. Trabalho } & \multirow{7}{*}{$\begin{array}{l}\text { Promoção de emprego pleno e } \\
\text { produtivo, trabalho decente para } \\
\text { todos, e proteção social }\end{array}$} & Emprego & \multirow{7}{*}{ 19. Trabalho } \\
\hline & & Trabalho/ Relações de gestão & \\
\hline & & Saúde e segurança ocupacional & \\
\hline & & $\begin{array}{l}\text { Liberdade de associação e } \\
\text { negociação coletiva }\end{array}$ & \\
\hline & & Trabalho infantil & \\
\hline & & $\begin{array}{l}\text { Prevenção do trabalho forçado e } \\
\text { compulsório }\end{array}$ & \\
\hline & & Práticas de segurança & \\
\hline 18. Transporte & Transporte sustentável & Transporte & 20. Transporte \\
\hline
\end{tabular}

\section{Fonte: Sistema FIEP - Observatórios SESI SENAI IEL (2012).}


A segunda proposta de áreas temáticas, apresentada no Quadro 7, foi ajustada quanto à sua terminologia e sobreposições entre as áreas sugeridas, culminando em terceira proposta de áreas passíveis de uso para investigação em indústrias localizadas no estado do Paraná (Quadro 8).

\begin{tabular}{|c|c|}
\hline PROPOSTA 2 DE ÁREAS TEMÁTICAS & PROPOSTA 3 DE ÁREAS TEMÁTICAS \\
\hline 1. Água & 1. Água \\
\hline 2. Atmosfera & 2. $\mathrm{Ar}$ \\
\hline 3. Consumo & 3. Consumo consciente \\
\hline 4. Clima & 4. Mudanças climáticas \\
\hline 5. Demografia & 5. Território \\
\hline 6. Diversidade e lgualdade de gênero & 6. Igualdade de gênero e diversidade \\
\hline 7. Direitos & 7. Direitos humanos \\
\hline 8. Recursos Naturais & 8. Conservação ambiental \\
\hline 9. Educaçäo & 9. Educação \\
\hline 10. Efeitos atividades humanas & 10. Riscos e desastres \\
\hline 11. Corrupçẫo & 11. Compromissos éticos \\
\hline 12. Governança & 12. Governança pública \\
\hline 13. Inovação & 13. Inovação socioambiental \\
\hline 14. Oceanos, mares e regiöes costeiras & 14. Mares e oceanos \\
\hline 15. Produção & 15. Produção mais limpa \\
\hline 16. Recursos energéticos & 16. Energia \\
\hline 17. Residuos & 17. Residuos e lixo \\
\hline 18. Solo & Area tematica incorporada a outras \\
\hline 19. Trabalho & 18. Trabalho \\
\hline 20. Transporte & 19. Transporte \\
\hline Area temática criada & 20. Organização e gestão \\
\hline
\end{tabular}

Fonte: Sistema FIEP - Observatórios SESI SENAI IEL (2012).

A terceira proposta de áreas temáticas, apresentada no Quadro 8, analisada, levou a eliminar áreas devido à sua complementaridade e sobreposição de conceitos idênticos tratados em temas distintos. Para eliminar tais fatores, visando a clareza e a delimitação do conteúdo de cada tema, os aspectos Território, Igualdade de gênero e diversidade, Mares e oceanos, Resíduos e lixo e Transporte foram incorporados a áreas que os contextualizaram, como Direitos humanos, Produção, Energia, Água, Trabalho. Os temas Conservação ambiental e Produção mais limpa passaram ainda por tratamento de nomenclatura, resultando em respectivamente Conservação e Produção, cujo foco passou a ser ampliado.

Assim, elaborou-se a proposta em uso de áreas temáticas de sustentabilidade a serem investigadas em indústrias localizadas no Paraná (Figura 2). 


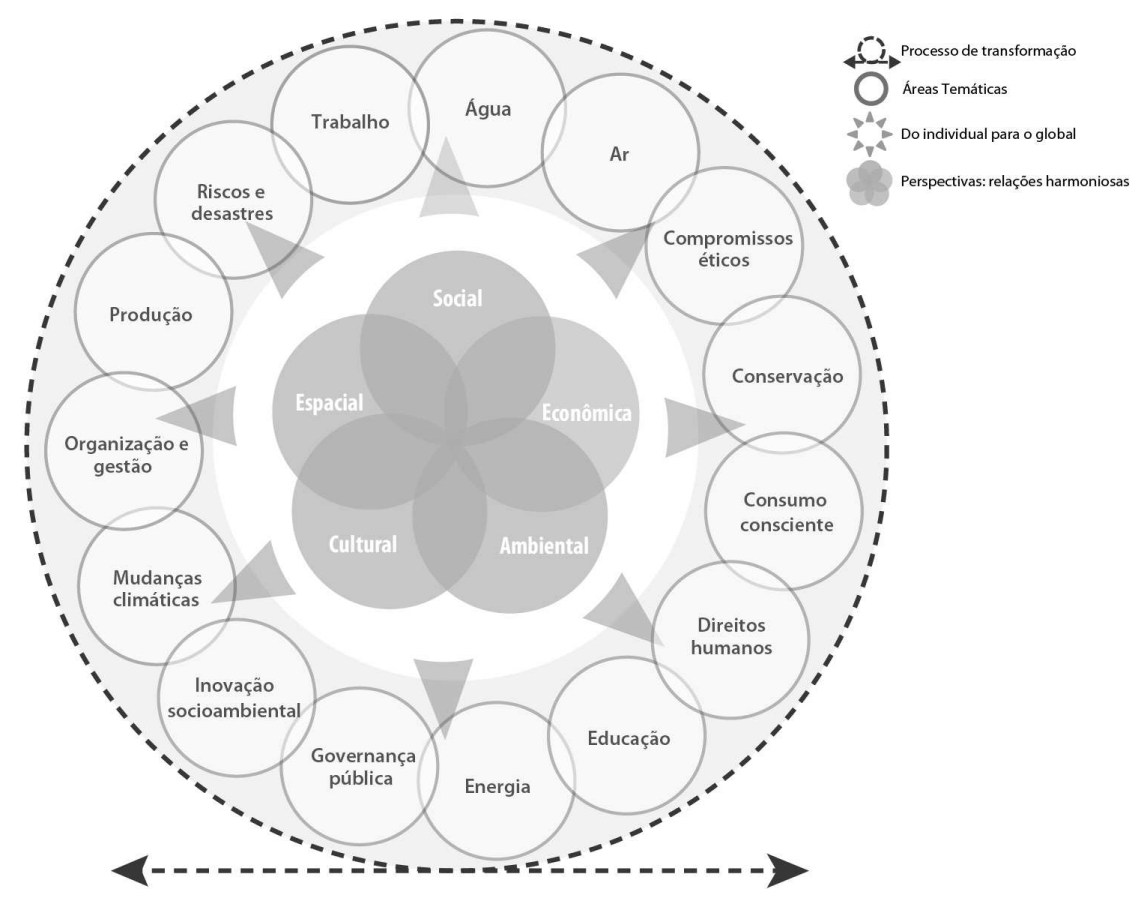

Fonte: Sistema FIEP - Observatórios SESI SENAI IEL (2013).

Esta estrutura leva em consideração a relação entre as áreas temáticas propostas e as dimensões de sustentabilidade abordadas por Sachs (1993), selecionadas no início do estudo. Para essa proposta foram identificadas 15 áreas temáticas que representam aspectos de sustentabilidade e circundam as citadas perspectivas, na ilustração. As relações harmônicas entre perspectivas, o dinamismo da transformação baseada na integração entre as áreas e a direção dos esforços (do individual para o global) também são explicitados no modelo.

\section{CONSIDERAÇÕES FINAIS}

A pesquisa, cujos procedimentos metodológicos e resultados são sintetizados neste artigo, teve como objetivo geral: identificar áreas temáticas de sustentabilidade comumente observadas em documentos referenciais e de mensuração relacionados ao tema, com potencial para uso em pesquisa junto às indústrias de transformação localizadas no Paraná.

Considera-se atendido este objetivo, já que documentos referenciais e de mensuração sobre sustentabilidade foram identificados, viabilizando a análise de seu conteúdo, representativo da temática nos contextos internacional e nacional, e 
efetivamente utilizado como ponto de partida para delimitar categorias de análise dos referidos documentos, com foco em princípios, critérios e indicadores de sustentabilidade. Tais conteúdos foram compilados e tratados com auxílio de suporte tecnológico, de maneira orientada a áreas temáticas de sustentabilidade, culminando nas efetivas áreas delimitadas para o uso pretendido da pesquisa.

A análise de conteúdo mostrou-se um método rico em técnicas aplicáveis ao cumprimento do objetivo da pesquisa relatada, permitindo que se pudesse observar criticamente o conteúdo selecionado para estudo e, ao mesmo tempo, documentar tal observação por meio de tecnologia de suporte. A base de conteúdos resgatados e de comentários acerca destes em relação à temática da sustentabilidade, atribuiu um continuum ao esforço de subsidiar a identificação de áreas temáticas, uma vez que pesquisadores puderam cumprir tal tarefa em conjunto, e em momentos não necessariamente simultâneos.

Tratar de conteúdos referenciais com escopos distintos como princípios, critérios e indicadores de sustentabilidade exigiu que se mantivessem padrões de leitura e tratamento dos documentos utilizados como base para a pesquisa. Essa necessidade foi suprida pelas técnicas de leitura e tratamento utilizadas a partir do método da análise de conteúdo, que se considera adequado para fins de pesquisa similares a esta.

Os resultados alcançados mediante aplicação dessas técnicas atenderam à expectativa da pesquisa, permitindo alcançar um modelo final, aplicável à realidade do Programa no qual o estudo esteve inserido. Destaca-se que a proposta de áreas temáticas e suas relações diretas com perspectivas de sustentabilidade aplica-se somente à pesquisa em questão, sendo que para outras iniciativas, são necessárias adequações de escopo e conteúdo em relação aos procedimentos relatados neste artigo.

Como sugestões para trabalhos a serem realizados a partir deste, são vislumbradas as seguintes abordagens:

a) complementação da lista de documentos referenciais e de mensuração utilizada para compor as áreas temáticas de sustentabilidade delimitadas nesta pesquisa;

b) realização de estudos relacionados à análise de aspectos da sustentabilidade em outros estados do Brasil e mesmo no exterior; 
c) aplicação dos procedimentos metodológicos aqui descritos com foco em outras temáticas e abordagens de pesquisa, ampliando o rol de aplicações da análise de conteúdo em diversos contextos.

\section{REFERÊNCIAS}

ARAÚJO, Geraldino C. et al. Sustentabilidade empresarial: conceito e indicadores. In: CONGRESSO VIRTUAL BRASILEIRO DE ADMINISTRAÇÃO, 3., 2006. Anais... 2006. Disponível em:

<http://buscatextual.cnpq.br/buscatextual/visualizacv.do?id=K4732598Z4>. Acesso em: 03 jul. 2013.

BARATA, Martha M. L. O setor empresarial e a sustentabilidade no Brasil. Revista Pensamento Contemporâneo em Administração (UFF), v. 1, p. 1/6-20, 2007.

BARDIN, Lawrence. Análise de conteúdo. São Paulo: Edições 70, 2011.

BARONI, Margaret. Ambiguidades e deficiências do conceito de desenvolvimento sustentável. Revista de Administração de Empresas, São Paulo, v. 32, n. 2, p. 1424, 1992.

BAZZO, Walter A.; LINSINGEN, Irlan von; PEREIRA, Luiz T. do V. O que é Ciência, Tecnologia e Sociedade? In: BAZZO, Walter A.; LINSINGEN, Irlan von; PEREIRA, Luiz T. do V. Introdução aos estudos CTS (ciência, tecnologia e sociedade). Espanha: OEI, 2003.

BOSSEL, Hartmut. Indicators for sustainable development: Theory, Method, Applications. Winnipeg: International Institute for Sustainable Development, 1999. Disponível em: <http://www.iisd.org/pdf/balatonreport.pdf>. Acesso em: 15 jun. 2013.

COMISSÃO MUNDIAL SOBRE MEIO AMBIENTE E DESENVOLVIMENTO. Nosso Futuro Comum. Rio de Janeiro: Fundação Getúlio Vargas, 1988.

CONFEDERAÇÃO NACIONAL DA INDÚSTRIA. A indústria brasileira no caminho da sustentabilidade. Brasília, 2012. Disponível em:

<http://www.cnisustentabilidade.com.br/docs/CNI_PARTE_1_RIO20_web.pdf>. Acesso em: 17 mai. 2013.

CUTCLIFFE, Stephen. La emergência de CTS como campo acadêmico. In: CUTCLIFFE, Stephen. Ideas, máquinas y valores: los estudios de ciencia, tecnologia y sociedad. Barcelona: Anthropos, 2003. p. 7-24.

FARFUS, Daniele et al. Indicadores de desenvolvimento sustentável que não geram índices. In: SILVA, Christian L. da; SOUZA-LIMA, José E. de (Org.). Políticas públicas e indicadores para o desenvolvimento sustentável. São Paulo: Saraiva, 2010.

FEDERAÇÃO DAS INDÚSTRIAS DO ESTADO DO PARANÁ. Disponível em: <www.fiepr.org.br>. Acesso em: 30 out. 2013. 
GIL, Antonio C. Como elaborar projetos de pesquisa. 5. ed. São Paulo: Atlas, 2010.

GLOBAL REPORTING INITIATIVE. Sustainability Reporting Guidelines. Disponível em: <https://www.globalreporting.org/reporting/G3andG3-1/guidelinesonline/Pages/default.aspx>. Acesso em: 05 set. 2012.

HARDI, Peter; ZDAN, Terrence J. Assessing sustainable development: principles in practice. Winnipeg: International Institute for Sustainable Development, 1997. Disponível em: <http://www.iisd.org/pdf/bellagio.pdf>. Acesso em: 05 jul. 2013.

INSTITUTO BRASILEIRO DE GEOGRAFIA E ESTATÍSTICA. Indicadores de desenvolvimento sustentável: Brasil. Rio de Janeiro: IBGE, 2010. Disponível em: <http://www.ibge.gov.br/home/geociencias/recursosnaturais/ids/ids2010.pdf>. Acesso em: 01 ago. 2013.

INSTITUTO ETHOS DE EMPRESAS E RESPONSABILIDADE SOCIAL. Indicadores de Responsabilidade Social e Empresarial. São Paulo: ETHOS, 2007. Disponível em: <http://www3.ethos.org.br/wpcontent/uploads/2012/07/IndicadoresEthos_2012_PORT-2.pdf>. Acesso em: 28 out. 2013.

LOUETTE, Anne (Org.). Gestão do conhecimento: compêndio para a sustentabilidade - ferramentas de gestão de responsabilidade socioambiental. São Paulo: Antakarana Cultura, Arte e Ciência, 2008.

MEZOMO, Jocilane; CORONA, Hieda M. P.; VASCO, Ana P. D. Indicadores de sustentabilidade do Instituto Ethos e o processo de gestão das indústrias associadas a FIEP, no município de Pato Branco. In: V ENANPPAS, 2010, Florianópolis. Anppas 10 anos: avaliando os desafios teóricos e as novas agendas públicas. Florianópolis: UFSC, 2010.

SISTEMA FIEP. Observatórios SESI SENAI IEL. Programa Bússola da Sustentabilidade: caderno metodológico do projeto 4. 2012. Documento interno.

SISTEMA FIEP. Observatórios SESI SENAI IEL. Programa Bússola da Sustentabilidade: escopo. 2013. Documento interno.

SACHS, Ignacy. Estratégias de transição para o século XXI: desenvolvimento e meio ambiente. Tradução: Magda Lopes. São Paulo: Studio Nobel e Fundação do Desenvolvimento Administrativo, 1993.

SILVA, Christian L. da. Desenvolvimento sustentável: um conceito multidisciplinar. In: SILVA, Christian L. da; MENDES, Judas T. G. (Org.). Reflexões sobre o desenvolvimento sustentável: agentes e interações sob a ótica multidisciplinar. Petrópolis: Vozes, 2005.

UNITED NATIONS. Indicators of sustainable development: guidelines and methodologies. $3^{\text {rd }}$ ed. New York: United Nations, 2007. Disponível em: <http://www.un.org/esa/sustdev/natlinfo/indicators/guidelines.pdf >. Acesso em: 21 abr. 2013. 
UNITED NATIONS. The future we want. ONU: Rio de Janeiro, 2012. Disponível em: <http://www.uncsd2012.org/content/documents/727The\%20Future\%20We\%20Want \%2019\%20June\%201230pm.pdf>. Acesso em: 05 set. 2012).

UNITED NATIONS INDUSTRIAL DEVELOPMENT ORGANIZATION. UNIDO business partnerships for industrial development. Vienna, 2002. Disponível em: <http://www.unido.org/fileadmin/user_media/Publications/Pub_free/Partnership_guid e.pdf> Acesso em: 10 mai. 2013.

VAN BELLEN, Hans Michael. Indicadores de sustentabilidade: uma análise comparativa. 2002. 220f. Tese (Doutorado em Engenharia da Produção) Universidade Federal de Santa Catarina, Florianópolis, 2002. Disponível em: <http://www.tede.ufsc.br/teses/PEPS2761.pdf>. Acesso em: 21 ago. 2013. 